\title{
LA VISIÓN DEL ANTIGUO EGIPTO EN LA RIHLA DE IBN ŶUBAYR
}

\section{$M^{a}$ Carmen Carriazo Rubio}

El interés que ha despertado el Antiguo Egipto a lo largo de los siglos no es algo novedoso. Numerosísimas son, sin duda, las páginas dedicadas al estudio de su historia y de sus monumentos. De hecho, aún en nuestros días, el mundo de los faraones continúa atrayendo las miradas de multitud de investigadores, viajeros y curiosos. Sin embargo, propongo que en las líneas que ahora siguen nos detengamos en el análisis de la visión particular de un autor concreto. Me refiero a la que aporta Ibn Ŷubayr en su obra ${ }^{1}$.

Bajo el nombre de rihla se conoce - como es sabido- el género literario, aparecido en al-Andalus a partir del siglo XII, consistente en relatos de viajeros que habían realizado la peregrinación a La Meca ${ }^{2}$. Por ello, se convierten, según C. Pellat, en «verdaderas guías para el uso de los futuros peregrinos» ${ }^{3}$. Pero, aunque el motivo central de este tipo de obras es la minuciosa descripción de los Lugares Santos, en realidad, al ser escritos que poseen una finalidad práctica evidente, engloban comentarios de muy diversa índole.

El autor reconocido por todos como creador de la rihla es el valenciano Ibn Yubayr (11451217), quien se convirtió en modelo indiscutible para los literatos posteriores ${ }^{4}$. Tras realizar sus estudios en Játiva, se marchó a Granada, donde ejerció de secretario bajo mandato del gobernador almohade $\mathrm{Abu} \mathrm{Sa}^{\mathrm{c}} \overline{1} \mathrm{C}^{\mathrm{c}} \mathrm{U} \operatorname{timān} \mathrm{b}$. ${ }^{\mathrm{c}} \mathrm{Abd}$ al-Mu'min. Se cuenta que fue éste quien un día le obligó a beber siete copas de vino y que, tras dicho suceso, se la llenó siete veces de monedas de oro. Con ese dinero decidió hacer la peregrinación a La Meca para expiar su falta, de la que se arrepentía amargamente. Así, encaminó sus pasos hacia Oriente en febrero de

' Ibn Ŷubayr, Rihla, Beirut, 1980, cuya traducción ha sido tomada de F. Maíllo, A través del Oriente. El siglo XII ante los ojos, Barcelona, 1988. Otros testimonios medievales sobre el Antiguo Egipto han sido comentados por U. Haarmann, "Medieval muslim perceptions of pharaonic Egypt", Ancient Egyptian Literature. History and Forms, ed. A. Loprieno, Leiden, 1996, 605-627.

${ }^{2}$ Véase I. R. Netton, s.v. "rihla", Encyclopédie de l'Islam, t. VIII, París, 1990, 545-546; en adelante, aparecerá citada como E. I., $2^{\mathrm{a}}$ ed.

${ }^{3}$ C. Pellat, Langue et littérature arabes, París, 1952, 183.

${ }^{4}$ Aunque, al parecer, la primera rihla fue compuesta por Ibn 'Arabī (1076-1148), dicha obra no se ha conservado, Ibídem. Además, se ha hablado de unos posibles antecedentes de este género, en concreto, de algunos relatos de viajes, tales como la Relación de China y de la India o Las Maravillas de la India, que datan de los siglos IX y X respectivamente. Sin embargo, conviene advertir que éstas consistían, más bien, en una sucesión de aventuras fantásticas ocurridas a los marinos y mercaderes que osaban dirigirse a aquellas tierras; véase el capítulo IV dedicado a "las gentes del viaje" por A. Miquel, La géographie humaine du monde musulman jusqu'au milieu du $11^{\text {ème }}$ siècle, París, 1967, t. I, 113-152. 
1183 , de donde regresaría dos años después, en abril de 1185 , periodo que ha quedado fielmente reflejado en su obra. Aunque realizó otros dos viajes a tierras orientales, no nos dejó testimonio escrito, pero sabemos que en el último —emprendido en el año 1217—decidió fijar su residencia en Alejandría para dedicarse a la enseñanza, ciudad en la que encontraría la muerte pasados algunos meses 5 .

Hoy es recordado como literato, por sus versos y sentencias, pero su nombre evoca, ante todo, al de un viajero, autor de una obra que él mismo llamó Tadkira bi-ajbār ${ }^{c}$ an ittifāqāt alasfär o Relación acerca de las noticias concernientes a los sucesos de los viajes ${ }^{6}$. En ella Ibn Ŷuayr distingue en todo momento lo real de lo imaginario, gracias al testimonio visual y directo - conocido como ${ }^{c} i y \bar{a}$-, contrastando, a su vez, los datos que ofrece con aportaciones anteriores, ya sean tradiciones orales o fuentes escritas.

De esta manera nos ha legado un texto fiable y bien documentado en el que la acción se desarrolla de manera cronológica, aunque el relato comienza en el mar, el 25 de marzo de 1183 , frente a las costas de al-Andalus, y se remonta, poco después, a la salida desde Granada, al anochecer del día 3 de febrero del mismo año. En cualquier caso, las anécdotas se suceden linealmente hasta su regreso a Granada, el 25 de abril de 1185. Las peripecias de su viaje le llevaron a atravesar mares y visitar ciudades muy diversas. Fueron dos años llenos de aventuras que Ibn Ŷubayr no dudó en registrar con todo detalle. Ahora son páginas repletas de datos de sumo interés, entre los que destacan, como es lógico, aquellos relacionados con la peregrinación.

Pero la mirada de Ibn Ŷubayr va más allá del motivo de su viaje. A partir de sus observaciones podrían realizarse infinidad de reflexiones de carácter histórico, político, social, económico o geográfico, en las que no nos vamos a detener ${ }^{7}$. No cabe duda de que, como ya apuntara F. Gabrieli, este autor «mantiene los ojos abiertos y curiosos sobre el áureo árbol de la vida $\mathrm{y}$, aun sin olvidar nunca que es un piadoso peregrino musulmán, no desdeña espectáculos profanos, descripciones de la naturaleza y de obras de arte» ${ }^{8}$. Pues bien, es esa curiosidad "profana" la que nos ha proporcionado testimonios únicos sobre el Antiguo Egipto; testimonios que, como vamos a ver, merecen ser analizados con detenimiento.

5 Sobre los datos biográficos del autor véanse, entre otros, Ibn Ŷubayr, Rihla, ed. 5-6/ trad. 20-24; C. Pellat, s.v. "Ibn Diubayr", E. I., $2^{\text {a }}$ ed., t. III, 777-778; F. Pons Boigues, Ensayo bio-bibliográfico sobre los historiadores y geógrafos arábigo-españoles, Madrid, 1993, ed. facsímil de la de 1898, $\mathrm{n}^{\circ}$ 225, 267-268 y AA.VV., Voyageurs arabes: Ibn Fadlān, Ibn Jubayr, Ibn Battựta et un auteur anonyme, textes traduits, présentés et annotés par Paule CharlesDominique, París, 1995, 1089-1090.

${ }^{6}$ AA.VV., Voyageurs arabes, 1090-1091.

${ }^{7}$ De hecho, existen estudios específicos, como el referido a la navegación en el siglo XII de A. Gateau, "Quelques observations sur l'intérêt du voyage d'Ibn Jubayr pour l'histoire de la navigation en Méditerranée au XII siècle", Hespéris, XXXVI (1949), 289-312.

${ }^{8}$ F. Gabrieli, La literatura árabe, Buenos Aires, 1971, 216. 
Resulta lógico pensar que un viajero andalusí del siglo XII sintiera asombro, admiración y curiosidad frente a las pirámides de Gizeh, frente a la esfinge o ante el templo de Ijmīm (Panópolis). Sin embargo, ahora son sus palabras las que sorprenden a cualquier lector, al comprobar la minuciosidad de sus descripciones y el orden en su exposición. Sin duda, se trata de un observador guiado por un gran afán de conocimiento, al que le atrae todo lo desconocido y novedoso.

Ahora bien, en sus planteamientos hay algo que capta nuestra atención de manera especial. Quizás parezca anacrónico o, al menos, inusual para su época, pero lo cierto es que en Ibn Ŷubayr la simple curiosidad se transforma en un espíritu que me atrevería a calificar de "científico". Se detiene ante cada detalle, se fija en el sistema constructivo, así como en los materiales empleados y en el estado de conservación de los monumentos y, lo más importante, se cuestiona el origen y la finalidad de los edificios que observa. Un buen ejemplo es el relato siguiente referido a las pirámides:

Cerca de este puente nuevo están las antiguas pirámides, construcciones maravillosas, espectáculo extraordinario; son de forma cuadrada como si fuesen vastas tiendas plantadas, alzándose en el aire del cielo, especialmente dos de ellas; pues esas dos llenan en altura el espacio aéreo (ŷaww). La anchura de una de ellas, desde una de sus esquinas a la otra, es de 366 pasos. Han sido levantadas con enormes piedras talladas, ensambladas de forma impresionante en insólita cohesión, sin que haya habido, para ayudarse, que rellenar los intersticios. A primera vista [tienen] los bordes angulosos, mas como es posible la subida a ellas, aunque con peligro y trabajo, entonces se descubre que sus angulosos bordes presentan como superficies planas bien anchas. Si las gentes de la tierra deseasen demoler su construcción les sería imposible. Se difiere en lo relativo a su origen; a unos se les antojan tumbas para ${ }^{c} \bar{A} d$ y sus hijos; otros pretenden otra cosa. En resumidas cuentas nadie sabe lo que son, salvo Dios, poderoso y grande.

Una de las dos grandes tiene una puerta, por la que se sube a ella, que está de la tierra aproximadamente a la estatura de un hombre o más; se penetra por ella a un gran aposento, cuya anchura es de cerca de cincuenta palmos y su longitud de más o menos eso. Al fondo de este aposento hay un largo [bloque de] mármol ahuecado, semejante a lo que el pueblo ('āmma) llama pīla (ㅁila), que se dice es una tumba, pero Dios sabe mejor la verdad de eso ${ }^{9}$.

Posiblemente, cuando Ibn Ŷubayr quiso dejar constancia de estas obras de arte no fuera consciente del alcance de sus palabras. En cambio, ahora, con la perspectiva que nos ofrece el tiempo, advertimos múltiples aspectos dignos de comentar. En primer lugar, no debemos olvidar las circunstancias que envuelven la redacción de estas líneas, puesto que, como bien apunta M. Marín, «cualquier relación de viaje es tan informativa de lo que se ha visto como de quién lo ha visto y por qué» ${ }^{10}$. De hecho, sabemos que son las anotaciones de un viajero musulmán, pero, aunque no conociéramos a su autor, el texto nos permitiría deducirlo. Basta con reparar en las continuas referencias a Dios o en esa curiosa comparación de las pirámides

9 Ibn Ŷubayr, Riḥla, ed. 28/ trad. 71-72.

${ }^{10}$ M. Marín, "Periplos culturales", Al-Andalus y el Mediterráneo, Barcelona, 1995, 123. 
con «vastas tiendas plantadas, alzándose en el aire», como si de jaimas en medio del desierto se tratara. Es lógico pensar que el asombro experimentado ante elementos completamente ajenos a su cultura le inspire imágenes referidas al entorno cotidiano, capaces de transmitir al lector de su época la realidad que él está observando.

Lo mismo le sucederá ante la esfinge, que asemeja esta vez a una construcción típicamente islámica, diciendo que "en la proximidad de estas pirámides, a distancia de un tiro de flecha, hay una extraña figura de piedra que se alza como un alminar ${ }^{11}$. Esto nos hace recordar que «un viaje a regiones desconocidas con anterioridad es, antes que ninguna otra cosa, un traslado de la mente del viajero, que registra novedades y coincidencias con su paisaje mental (y físico) habitual» ${ }^{12}$.

Por otra parte, en la descripción de las pirámides comprobamos que es cierta la minuciosidad mencionada, pues el autor alude a las piedras utilizadas en su construcción, a la manera de ensamblarlas, a las medidas y a una serie de detalles derivados de la observación directa, es decir, del ciyān. De hecho, resulta más que probable que el propio Ibn Ŷubayr realizara el esfuerzo de subir a ellas para examinar de cerca tanto su aspecto externo como lo que se ocultaba en su interior: aquella pila «que se dice que es una tumba» ${ }^{13}$.

Sin embargo, a pesar de lo acertado, no parece convencerle especialmente esta solución, sin duda, porque las leyendas en torno a los orígenes de las pirámides debían ser muy abundantes y variadas. La finalidad de estas construcciones era un auténtico misterio que nadie conseguía explicar ${ }^{14}$. Ibn Ŷubayr recoge una de las versiones que habla también de ellas como lugar de enterramiento, pero reservado a ${ }^{c} \bar{A} d$ y sus hijos. En cuanto a ${ }^{c} \bar{A} d$, es preciso aclarar que se trata del epónimo de una tribu semítica de Arabia meridional que vivió inmediatamente después de Noé y que fue exterminada por Dios al no haber querido escuchar al profeta Hūd ${ }^{15}$.

${ }^{11}$ Ibn Ŷubayr, Rihla, ed. 29/ trad. 72.

${ }^{12}$ M. Marín, "Periplos culturales", 123.

${ }_{13}$ No olvidemos que el hecho de escalar monumentos faraónicos era una práctica frecuente en época medieval, tal y como hiciera Muhammad al-'Ubaydalī al-Halabī (m. 1267). De hecho, sabemos que durante el visirato de Ṭalā'i ${ }^{c}$ b. Ruzzīz (m. 1161) un temerario escalador murió al precipitarse desde lo alto de la pirámide de Kefrén. El peligro no impidió que diversos aventureros intentaran acceder a la cima de la pirámide de Keops, tarea, en principio, más sencilla. Al parecer, contaron incluso con remuneraciones ofrecidas por las autoridades; U. Haarmann, "Medieval muslim perceptions", 609 y 614.

${ }^{14}$ Algunas interpretaciones hablan de ellas como graneros de José, mientras que otras enumeran entre sus posibles constructores al «rey Shaddād b. 'Ād, el babilonio Hermes, treinta descendientes consecutivos de Bayṣar b. Hāam, el nieto de Noé, y final y más sorprendentemente incluso, Aristóteles. Se dice que este último erigió las dos grandes pirámides ([...] de Kheops y Khephren) como mausoleos para él mismo y para su discípulo Alejandro Magno», Idem, 607 y $609-610$

${ }^{15}$ Sobre este pueblo mítico véanse F. Buhl, s.v." $\mathrm{A} d "$, E. I., $2^{\mathrm{a}}$ ed., t. I, 174 y El Corán, trad. de J. Cortés, Barcelona, 1986, 7; 65-72, 221. 
Además, los aditas eran famosos por su corpulencia y de ahí que la tradición los considere autores de muchas de las grandes obras arquitectónicas de la Humanidad ${ }^{16}$.

Según nos cuenta en el siglo XIV Ibn Jaldūn"17, "el vulgo da el nombre de "vestigios aditas" a la mayor parte de los edificios que subsisten todavía en nuestros días, los atribuyen al pueblo de Aad; porque se imaginan que sus construcciones y sus edificios han debido ser de una magnitud extraordinaria por razón de la talla gigantesca y de las enormes fuerzas que se suponen a los individuos de dicho pueblo. Tal idea, no obstante, carece de todo fundamento, pues vemos numerosos monumentos erigidos por hombres que pertenecieron a naciones cuya talla nos es perfectamente conocida, y esos monumentos sin embargo igualan y superan incluso en magnitud a los (que se atribuyen a los Aaditas)» ${ }^{18}$.

Como vemos, este autor sí nos advierte del error, pues explica cómo muchos «se imaginan que esas construcciones son debidas a la sola fuerza natural de ciertos hombres que habian trabajado en ellas, ya sea aisladamente, o reunidos en grupos; en consecuencia, suponen que la talla de esos hombres correspondía a las dimensiones de esas obras, y que eran muy superiores en altura, corpulencia y fuerza a los de la actualidad; y eso, porque existía alguna proporción entre los cuerpos de dichos hombres y las fuerzas que habian producido a tales obras. Mas, en ese (falso cálculo), no se tiene en cuenta alguna el recurso de la mecánica, del cabrestante y de otros instrumentos cuyo empleo, en parecidos casos, es exigido por el arte de la ingeniería» ${ }^{19}$.

Es cierto que Ibn Ŷubayr no desmiente la hipótesis tradicional, como haría más tarde Ibn Jaldūn, pero también hay que reconocer que se muestra bastante escéptico y desinteresado ante las explicaciones legendarias, a las que no les concede más de dos líneas en su descripción. En cambio, en contraposición con esa mirada "científica" hallamos otra quizás más crédula y más ingenua que la de su antecesor. Me refiero a la del famoso viajero del siglo XIV llamado Ibn Battūtạta

Las pirámides y templos se cuentan entre las maravillas dignas de mención a lo largo de la Historia. Mucho han hablado las gentes sobre ellos, tratando de descifrar su objeto y antigüedad. Hay quienes pretenden que todas las ciencias aparecidas antes del

${ }^{16}$ Una aleya coránica hace alusión a dicha característica, quizá en sentido figurado y refiriéndose, más bien, al poder que ejercían en su territorio, pero en cualquier caso la cita dice así: «Y recordad cuando os hizo sucesores después del pueblo de Noé y os hizo corpulentos», El Corán, 7; 69, 221.

${ }^{17}$ Sobre este autor tunecino, considerado historiador, sociólogo y filósofo, véase M. Talbi, s.v. "Ibn Khaldūn", E. I., $2^{\mathrm{a}}$ ed., t. III, 849-855.

18 Ibn Jaldūn, Muqaddima, Beirut, 1970, t. II, 206, ed. facsímil de Prolégomènes d'Ebn-Khaldoun. Texte arabe publié, d'après les manuscrits de la bibliothèque impériale, par M. Quatremère (París 1858), cuya traducción ha sido tomada de la Introducción a la Historia Universal (Al-Muqaddimah), ed. E. Trabulse, Méjico, 1977, 613.

${ }^{19}$ Idem, ed. 205/ trad. 612. En cuanto al problema de la construcción de las pirámides, por el que se interesan ciertos autores medievales, véase U. Haarmann, "Medieval muslim perceptions", 616.

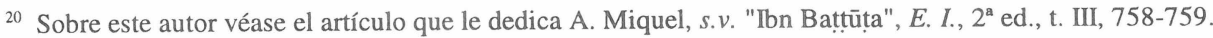


Diluvio procedían de Hermes, el Primero, que residía en los confines del Alto Egipto y era conocido por Junüj, es decir, Idrīs [Enoch] y que sería el primero en hablar del movimiento de los astros y de las sustancias superiores, y en elevar altares glorificando a Dios el Altísimo. También advirtió a los hombres el advenimiento del Diluvio, y temiendo la desaparición de la ciencia y la pérdida de las técnicas construyó pirámides y templos en los que grabó la totalidad de las artes y artilugios, dibujando las ciencias para perpetuarlas. [...]

Las pirámides están construidas de piedras sólidas labradas, de altura enorme, circulares, anchas de base, estrechas de cúspide. Parecidas a conos, sin puertas, y no se sabe cómo fueron edificadas. Se dice que uno de los reyes de Egipto antes del Diluvio tuvo visiones que le aterrorizaron y forzaron a levantarlas, en la margen occidental del Nilo, para que fuesen depósito de las ciencias al tiempo que enterramiento de los cadáveres reales. Inquirió a los estrelleros si tendrían alguna abertura y le notificaron que se abrirían por el flanco norte, indicándole el lugar por donde estaría el vano, así como el monto que alcanzaría abrirlo. Entonces mandó colocar en este sitio una cantidad equivalente a la comunicada por los astrólogos y se aplicó a la construcción, concluyéndola en sesenta años. E hizo escribir lo siguiente: "Construimos estas pirámides en sesenta años. Quien quiera, destrúyalas en seiscientos, aunque destruir es más fácil que construir"21.

El mismo autor incluye otro relato, quizás desconocido o tal vez desdeñado por Ibn Yubayr, referido a la destrucción de las pirámides:

Cuando el califato recayó en el Príncipe de los Creyentes al-Ma'mūn, le plugo destruirlas, pero algunos notables de Egipto le indicaron que no hiciera tal. Sin embargo, insistió en ello y ordenó que se abriese por el lado norte. Así pues, prendieron sobre las pirámides hogueras, las rociaron con vinagre y les dispararon con el almajaneque hasta que se abrió el hueco que existe hoy día. De este modo encontraron frente a la brecha una cantidad de dinero que el Príncipe de los Creyentes hizo pesar, al tiempo que se calculaban los gastos de la abertura, comprobándose que eran iguales. Esto dejó muy asombrado al califa. También descubrieron que el grosor del muro era de veinte codos ${ }^{22}$.

Por lo tanto, al comparar la visión que ambos viajeros plasmaron en sus respectivas obras sobre las mismas pirámides, percibimos claramente la diferencia. Queda reforzado así aquel espíritu "científico" que mencionábamos al principio como característica original del autor valenciano. Es más, llegados a este punto podríamos añadir que nos hallamos ante la atenta mirada de un "arqueólogo" medieval. Cierto es que puede resultar arriesgado hablar en el siglo XII de una ciencia - la arqueología - que no se consolida como tal hasta época

${ }^{21}$ Ibn Battūtạ, Rihla, Beirut-Líbano, 1987, 59-60, traducida por F. Arbós y S. Fanjul, A través del Islam, Madrid, 1993, 137-138. Y enlazando con esta última idea añade Ibn Jaldūn: «y no obstante que destruir es mucho más fácil que edificar: destruir, es hacer volver las cosas a su estado primitivo, que es la nada, mientras que edificar, es obrar directamente contra ese principio», Ibn Jaldūn, Muqaddima, ed. 208/ trad. 615.

22 Ibn Battūta, Rihla, ed. 60/ trad. 138-139. De nuevo Ibn Jaldūn se hace eco de esta noticia: «Otro tanto ocurrió a Almamún, cuando trató de destruir las pirámides de Egipto y agrupó los obreros para ese fin; no pudo lograr éxito alguno. Se empezó por hacer una abertura en una de las pirámides y se llegó hasta un espacio vacío entre el muro exterior y otro muro interior. Hasta allí se limitó la demolición. El pasaje que se practicó en ese monumento se ve todavía, según se dice. Algunas personas pretenden que Almamún encontró un tesoro entre esos muros. ¡Y Dios mejor lo sabe!», Ibn Jaldūn, Muqaddima, ed. 209/ trad. 616. 
contemporánea ${ }^{23}$. Sin embargo, recordemos las palabras de G. Daux, para quien «antes de llegar a ser una ciencia, la arqueología es una actitud» ${ }^{24}$.

Pues bien, ¿quién puede negar que Ibn Ŷubayr tuviera una actitud arqueológica en el siglo XII, si entendemos, al igual que J. Alcina Franch, que «esa actitud se manifiesta en un especial interés por los objetos y las obras de arte de eso que calificamos con un término tan vago como es el de "antigüedad" ${ }^{25}$ ? Bien es verdad que la historia de la arqueología suele ignorar, con frecuencia, la labor de los individuos que durante la Edad Media se preocuparon por analizar aquellos restos que habían heredado de civilizaciones anteriores. En cambio, se alude, a menudo, a las observaciones de los autores clásicos griegos, traducidas e interpretadas con posterioridad en el Renacimiento y, por supuesto, son de mención obligada la expedición napoleónica de finales del siglo XVIII o el descubrimiento de la piedra Rosetta; sin duda, hechos decisivos para el desarrollo de la arqueología actual ${ }^{26}$.

Sin embargo, desde el Islam medieval se aportan visiones interesantes, a veces diferentes y otras, únicas e irrepetibles, como sucede con las líneas dedicadas por Ibn Ŷubayr al templo de Ijmìm. Esta ciudad estaba situada en la orilla oriental del Nilo y fue la capital del nomo IX del Alto Egipto ${ }^{27}$. Su nombre en egipcio antiguo era Ipu o Khent-min y en copto, Khmin o Shmin, términos de los que derivan el griego Khemmis y el moderno Ijmīm o Ajmīm. Al identificar la divinidad local Min con el Pan griego, esta localidad fue conocida también en la Antigüedad clásica como Panópolis ${ }^{28}$.

Lamentablemente, no ha llegado hasta nosotros ningún vestigio de sus templos, ya que a lo largo de la Edad Media sus materiales fueron empleados en la construcción de las aldeas más próximas ${ }^{29}$. Al parecer, ambos se alzaban en la zona occidental de la ciudad y estaban

${ }^{23}$ En realidad, según apunta G. Daniel, «hubo que esperar hasta el siglo XIX, con el nacimiento de la prehistoria como disciplina científica, para que la arqueología encontrase al fin su propio campo de investigación: el estudio y la interpretación histórica de todos los restos materiales que las civilizaciones desaparecidas han dejado en la tierra», Historia de la arqueología. De los anticuarios a V. Gordon Childe, Madrid, 1986, 15.

${ }^{24}$ G. Daux, Les étapes de l'Archéologie, París, 1948, 18.

$25 \mathrm{~J}$. Alcina Franch, Arqueología antropológica, Madrid, 1989, 11.

26 Véanse, a manera de ejemplo, el capítulo I de D. L. Clarke, Arqueología analítica, Barcelona, 1984, 2-8, las páginas que sobre el estudio del Egipto antiguo incluyen J. Baines y J. Málek, Egipto. Dioses, templos y faraones, Barcelona, 1988, 22-29 o el libro de J. Vercoutter, Egipto, tras las huellas de los faraones, Madrid, 1989.

27 Es preciso aclarar que el nomo es la «denominación dada en la egiptología a las unidades administrativas territoriales, en las que estuvo dividido Egipto desde la III Dinastía aproximadamente. De forma ideal se diferenciaron 22 nomos en el Alto Egipto y 20 en el Bajo Egipto», M. Ullmann, "Glosario", Egipto. El mundo de los faraones, ed. R. Schulz y M. Seidel, Colonia, 1997, 517. Al parecer, «el número total de 42 nomos tenía un valor simbólico: 42 eran los jueces de los muertos, y un escritor cristiano de los primeros tiempos, Clemente de Alejandría (siglo II), afirma que los egipcios tenían 42 libros sagrados», J. Baines y J. Málek, Egipto, 15.

28 J. Baines y J. Málek, Egipto, 118.

29 Ibídem. 
consagrados a Min, el dios de la fertilidad, y a la diosa Repyt, su compañera ${ }^{30}$. Su importancia debió ser considerable, pues así lo hacen notar diversos geógrafos árabes, tales como Yāqūt, Idrīsī o Abū l-Fidā'i' .

No obstante, resulta curioso comprobar cómo la Rihla de Ibn Ŷubayr se ha convertido en la fuente de información más importante para reconstruir la imagen de un monumento hoy desaparecido. La ordenada descripción de sus dimensiones, columnas, techo, salas, azotea y decoración han permitido realizar estudios que nos acercan a la realidad de aquel emblemático edificio $^{32}$.

Por lo tanto, no cabe duda de que el valor de este testimonio es incalculable y de que la exhaustividad del autor adquiere aquí una especial relevancia. Pero el contenido de estas líneas no sólo nos permite la reconstrucción de un espacio perdido, sino que nos ofrece la oportunidad de establecer un curioso paralelismo entre nuestro viajero y uno de los arqueólogos más famosos de la historia: Howard Carter (1873-1939), a quien el descubrimiento de la conocida tumba de Tutankamón, durante el mes de noviembre de 1922, inspiró páginas sobrecogedoras.

Así, hoy vemos que aquel efecto «abrumador, impresionante» ${ }^{33}$ que experimentó Carter ante tan increíble hallazgo no se aleja demasiado del asombro que demostraba Ibn Ŷubayr dentro del templo de Ijmìm, donde «el conjunto forma una serie continua de maravillosas figuras y de colores extraordinarios $»^{34}$. Esas figuras «son conforme a [diferentes] variedades en cada una de las naves (balāt) del templo: una está cubierta de pájaros de claras formas, las alas desplegadas; el espectador creería que van a echar a volar. Otra está llena de figuras humanas de radiante aspecto y de espléndidas formas ${ }^{35}$.

${ }^{30}$ Idem, 118-119. El dios Min contó con otro centro importante de veneración en Coptos. «En la iconografía clásica, se le representa como una figura masculina, de pie y envuelta en vendas, que en una mano sostiene en alto un mayal mientras que, con la otra, sujeta por la raíz el pene erecto. Lleva un tocado consistente e un par de largas plumas. Otros atributos que le distinguen son una curiosa versión estilizada del primitivo santuario de campaña y una mata de lechugas cultivadas, cuya savia se interpretaba por lo visto como el semen del dios. También se le dio un emblema, que llevaba en lo alto de una vara; un objeto del cual todavía no se ha hecho una identificación categórica si bien, oportunamente, se le ha denominado "rayo"», B. J. Kemp, El Antiguo Egipto. Anatomía de una civilización, Barcelona, 1992, 109 y 112.

${ }^{31}$ Para Yāqūt «"fue uno de los más grandes y hermosos que hayan realizado la arquitectura y el arte". Idrīīī, por su parte, los contaba entre los templos más notables de Egipto. Abū-1-Fidā' lo llamaba "uno de los monumentos más célebres de la antigüedad"», S. Sauneron, Villes et légendes d'Égypte, París, 1983, 52.

${ }^{32}$ Idem, 51-61. A estas páginas llegué por la amabilidad del Dr. J. M. Serrano Delgado, profesor de Historia Antigua de la Universidad de Sevilla, a quien quiero agradecer el haber compartido conmigo sus extensos conocimientos sobre el Egipto faraónico.

${ }^{33}$ H. Carter, La tumba de Tutankamón, Barcelona, 1976, 52.

${ }^{34}$ Ibn Ŷubayr, Rihla, ed. 36/ trad. 82.

35 Idem, ed. 36-37/ trad. 82. 
Pues bien, esa imagen dinámica, ese realismo extremo es anotado ocho siglos más tarde por el descubridor británico, cuando nos describe el panel del respaldo de un trono como «una pequeña composición muy familiar y simple, pero también muy llena de vida y sentimiento y con gran sentido del movimiento ${ }^{36}$ o cuando se detiene ante las estatuas de unas diosas, pues «cada una de ellas protegía uno de los cuatro lados de la capilla, pero mientras que las figuras de la parte de delante y de detrás tenían su mirada fija en el objeto que estaba a su cargo, las otras dos añadían un conmovedor toque de realismo, ya que tenían la cabeza ladeada, mirando por encima de sus hombros hacia la entrada, como si vigilasen contra cualquier sorpresa ${ }^{37}$. Sin duda, observan objetos diferentes, pero desde una perspectiva común, por lo que el parecido de sus conclusiones resulta notable.

El asombro, en ocasiones, se transforma en una sensación más próxima al miedo. Temerosos se muestran también ambos autores. Si para Ibn Ŷubayr la esfinge poseía "características humanas de aterrador aspecto» ${ }^{38}$ y en el templo "hay imágenes de horrible aspecto, extrañas a la figura humana, que producen escalofríos de espanto al que las contempla, llenándole de inquietud ${ }^{39}$, dentro de la tumba del faraón nos cuenta Carter que «había tres sofás dorados cuyos lados estaban tallados en forma de animales monstruosos, de cuerpo curiosamente reducido para que cumplieran su cometido, pero con cabezas de sorprendente realismo. Estas bestias hubieran parecido extrañas en cualquier otra ocasión: vistas como lo hicimos nosotros, con sus brillantes superficies doradas destacando en la oscuridad como si tuvieran un halo propio gracias a nuestra linterna y sus cabezas proyectando sombras deformes y grotescas sobre la pared del fondo, eran casi aterradoras ${ }^{40}$. Luego ¿habría de sorprendernos ahora el parecido entre "el espectador, sobrecogido de admiración ${ }^{41}$ que nos presenta el viajero andalusí en el templo de Ijmìm y el propio Howard Carter, mirando hacia una puerta junto a la que estaba el más bello monumento que había visto en su vida, «tan hermoso que hace perder el aliento de asombro y admiración ${ }^{42}$ ?

Comparten, asimismo, intereses y preocupaciones. El arqueólogo se cuestiona el origen de lo observado para terminar afirmando que «en el transcurso de nuestro trabajo se hizo evidente que el grupo de enterradores egipcios debió encontrar grandes dificultades para levantar las capillas en un espacio tan reducido» ${ }^{43}$. Así, el viajero medieval, ejerciendo de "arqueólogo",

\footnotetext{
${ }^{36}$ H. Carter, La tumba, 68.

${ }^{37}$ Idem, 120.

${ }^{38}$ Ibn Ŷubayr, Rihla, ed. 29/ trad. 72.

39 Idem, ed. 37/ trad. 82-83.

${ }^{40}$ H. Carter, La tumba, 52.

${ }^{41}$ Ibn Ŷubayr, Rihla, ed. 37/ trad. 83.

${ }^{42}$ En esta ocasión se refiere a un gran cofre en forma de capilla, recubierto de oro y rodeado por cuatro estatuas de diosas; H. Carter, La tumba, 118.

${ }^{43}$ Idem, 152.
} 
al contemplar las grandes losas de piedra que constituyen el pavimento de la azotea del templo reconoce que, "como es en extremo elevada, la imaginación se pierde y la razón se extravía pensando cómo pudieron ser subidas y colocadas ${ }^{44}$.

En este sentido, su avanzada mentalidad científica le hace reparar en el estado de conservación del monumento. Apreciaciones como ésta son el resultado: «sus capiteles son de un tamaño y una perfección extrema, fueron tallados admirablemente; vienen a ser angulosos, de insólitas formas, como si los escultores (jarrāt) los hubieran recién acabado » ${ }^{45}$. Palabras muy parecidas emplea Carter cuando en 1922 encuentra una serie de arquetas de marfil y madera: «una de ellas, cuya tapa levantamos, contenía un maravilloso abanico de plumas de avestruz con empuñadura de marfil, aparentemente tan fresco y resistente como cuando lo terminó su autor» ${ }^{46}$.

En realidad, las detalladas observaciones de Howard Carter son las que cabría esperar para un arqueólogo de su época. Esas memorias que escribe a raíz del increíble hallazgo están llenas de la lógica emoción que embargaría a cualquier científico del siglo XX. Sin embargo, la mirada de Ibn Ŷubayr nos conduce hasta un autor que parece anticiparse a su tiempo. Esa modernidad es la que he querido subrayar a lo largo de estas páginas.

\footnotetext{
${ }^{44}$ Ibn Ŷubayr, Rihla, ed. 37/ trad. 83.

${ }^{45}$ Idem, ed. $36 /$ trad. 82.

${ }^{46}$ H. Carter, La tumba, 120.
} 